\title{
Factors Controlling the Rate of Perfluorooctanoic Acid Degradation in Laccase- mediator Systems: The Impact of Metal Ions
}

Qi Luo $^{\dagger}$, Zunyao Wang ${ }^{\ddagger}$, Mingbao Feng ${ }^{\ddagger}$, Dora Chiang ${ }^{\S}$, David Woodward ${ }^{\sharp}$, Shangtao Liang $^{\dagger}$, Junhe Lu ${ }^{\perp}$, Qingguo Huang ${ }^{\dagger *}$

${ }^{\dagger}$ Interdisciplinary Toxicology Program, Department of Crop and Soil Sciences, University of Georgia, Griffin, GA 30223, USA

${ }^{\ddagger}$ School of the Environment, Nanjing University, Nanjing, Jiangsu 210023, P. R. China

$\S$ AECOM Inc., Remediation Technology, Atlanta, GA 30309, USA

\# AECOM Inc., Remediation Technology, Mechanicsburg, PA 17055, USA

${ }^{\perp}$ College of Resources and Environmental Science, Nanjing Agricultural University, Nanjing, Jiangsu 210095, P. R. China

*Corresponding Author: e-mail: qhuang@uga.edu

Telephone: (770) 229-3302; Fax: (770) 412-4734 


\begin{abstract}
This study investigated the factors that regulated the degradation of perfluorooctanoic acid (PFOA) in laccase-catalyzed oxidative humification reactions with 1hydroxybenzotriazole (HBT) as a mediator. The reaction rates were examined under conditions with key factors varied, including initial PFOA concentrations, laccase and HBT dosages, and the ionic contents of the reaction solutions. The PFOA degradation followed pseudo-first order kinetics, and the rate constants $(k)$ were similar for the high (100 $\mu$ mole $\left.\mathrm{L}^{-1}\right)$ and low $\left(1.00 \mu\right.$ mole $\left.\mathrm{L}^{-1}\right)$ initial PFOA concentrations, respectively at 0.0040 day $^{-1}\left(r^{2}=0.98\right)$ and 0.0042 day $^{-1}\left(r^{2}=0.86\right)$ under an optimum reaction condition tested in this study. The metal ions contained in the reaction solution appeared to have a strong impact on PFOA degradation. Differential UV-Vis spectrometry revealed that $\mathrm{Cu}^{2+}$ can complex with PFOA, which plays an essential role to enable PFOA degradation, probably by bridging the negatively charged PFOA and laccase, so that the free radicals of HBT that are released from laccase can reach and react with PFOA. It was also found that $\mathrm{Fe}^{3+}$ plays a similar role as $\mathrm{Cu}^{2+}$ to enable PFOA degradation in the laccase-HBT reaction system. In contrast, $\mathrm{Mg}^{2+}$ and $\mathrm{Mn}^{2+}$ cannot complex with PFOA under the investigated conditions, and do not enable PFOA degradation in the laccase-HBT system. Fluoride and partially fluorinated compounds were detected as PFOA degradation products using ion chromatography and high resolution mass spectrometry. The structures of the products suggest the reaction pathways involving free-radical initiated decarboxylation, rearrangement, and cross-coupling.
\end{abstract}


Capsule: The factors that regulate the degradation of perfluorooctanoic acid (PFOA) in laccase-catalyzed oxidative humification reactions are identified and elucidated.

Keyword: Perfluorooctanoic acid; Enzyme catalyzed oxidative humification reactions; Laccase; Hydroxybenzotriazole mediator; Metal ions 


\section{Introduction}

A large quantity of perfluorooctanoic acid (PFOA) had been produced to meet the massive demand in various important industrial applications such as surfactant, fire retardant, and surface treatment (Paul et al., 2008; Prevedouros et al., 2006). The wide applications of PFOA are attributed to their extreme thermal and chemical stability as well as their hydrophobic and hydrophilic nature (Guo et al., 2008). These physicalchemical properties are derived from the unique structural feature of PFOA in which all hydrogens in the carbon-carbon skeleton are replaced by fluorines (O'Hagan, 2008). PFOA enters the environment primarily through emission from manufacturing facilities (Armitage et al., 2006), utilization of PFOA-based products (Ahrens, 2011), and transformation from polyfluoroalkyl precursors (Ruan et al., 2015). PFOA is prevalent in soil, groundwater, surface water, and sediment. The occurrence of PFOA in the Arctic ocean with limited anthropogenic impact has been reported at levels ranging from 3 to $259 \mathrm{pg} \mathrm{L}^{-1}$ (Benskin et al., 2012). Relatively high concentrations of PFOA are frequently observed near manufacturing plants, disposal sites, and fire-fighting training areas. For example, the groundwater collected from the firefighting training areas where the aqueous film-forming foams (AFFFs) were applied contained up to $219 \mu \mathrm{g} \mathrm{L}^{-1}(0.53$ $\mu$ mole $\mathrm{L}^{-1}$ ) of PFOA (Backe et al., 2013).

PFOA has drawn tremendous attention from both the public and the scientific community due to its potential adverse effects on human health and the environment (Renner, 2001). The potential health risks from exposure to PFOA include hepatic, reproductive, developmental, immunological, and endocrine system toxicity (Lau et al., 2007; Spachmo and Arukwe, 2012). In 2008, the European Food and Safety Authority 
has established a tolerable daily intake value for PFOA of $1.50 \mu \mathrm{g} \mathrm{kg}^{-1}$ body weight (EFSA, 2008). Numerous studies have been devoted to developing treatment and remediation techniques for PFOA contamination. Techniques such as electrochemical, photolytic, and sonochemical oxidation either involve high energy inputs or require special devices to achieve effective PFOA degradation (Gatto et al., 2015; Lin et al., 2012; Lin et al., 2015). A feasible treatment and remediation strategy is yet in need to address PFOA contamination.

Earlier studies indicated that enzyme catalyzed oxidative humification reactions (ECOHRs) were effective in degrading PFOA under environmentally relevant conditions, and thus potentially feasible for remediation applications (Colosi et al., 2009; Luo et al., 2015). ECOHRs are involved in natural humification processes mediating degradation of lignocellulosic materials as well as polymerization of small humic precursor molecules into humic substances. A number of extracellular enzymes such as peroxidases and phenol oxidases can mediate ECOHRs in soil (Guggenberger, 2005).

Laccases are a group of phenol oxidases that mediate ECOHRs, and have been well studied for their roles in the natural wood delignification process (Woolridge, 2014). Laccases can directly react with substrates containing phenolic or anilinic functional groups to convert them into active intermediates such as radicals and quinones (Du et al., 2013; Piccolo et al., 2000). These active intermediates can further react with recalcitrant organic matters such as lignin, one of the most persistent natural organic materials in the environment, to cause their degradation. Such laccase-mediator systems have been shown capable of degrading persistent organic pollutants (POPs) such as polychlorinated biphenyls (PCBs) (Keum and Li, 2004) and polycyclic aromatic hydrocarbons (PAHs) 
(Cañas et al., 2007; Johannes and Majcherczyk, 2000). The mediators such as 1hydorxybenzotriazole (HBT), vanillin, and ferulic acid have been used in these studies because of their high efficiency and low environmental impact (Cañas et al., 2007). These model mediators also contain functionalities that are commonly present in natural organic matter.

Our recent study revealed that $1.00 \mu$ mole $\mathrm{L}^{-1}$ PFOA in a mineral buffer was degraded about 50\% via ECOHRs after 157 days of incubation (Luo et al., 2015). It was proposed that the benzotriazole nitroxyl radical (BTNO) generated from HBT during ECOHRs induced the decarboxylation of perfluorocarboxylic acids (PFCAs) to form perfluoroalkyl radicals, which further reacted with other non-fluorinated free radicals also generated by ECOHRs to form partially fluorinated cross-coupling compounds.

In this study, we systematically evaluated the kinetics of PFOA degradation in laccase-HBT systems with key conditions varied, including PFOA and HBT concentrations and ionic composition, in an attempt to identify factors controlling the reaction rate. It was found in particular that the multivalent ions presented in the solution played a significant role, and the mechanism was elucidated. The results provide a basis to assess the feasibility of ECOHRs in PFOA remediation and approaches to optimize the process for potential application.

\section{Material and methods}

\subsection{Chemicals and reagents}

Perfluorooctanoic acid (PFOA), laccase from Pleurotus Ostreatus (EC 1.10.3.2), 1hydroxybenzotriazole (HBT), and 2,6-dimethoxyphenol (DMP) were purchased from Sigma-Aldrich (St. Louis, MO). Perfluorocarboxylic acids (PFCAs) with total carbon- 
chain length from $\mathrm{C} 4-\mathrm{C} 11$ and a surrogate standard perfluoro-n- $\left[{ }^{13} \mathrm{C} 8\right]$-octanoic acid (M8PFOA) were obtained from Wellington Laboratories (Ontario, Canada) (Supplementary Data Table S1). Cupric/magnesium/manganese sulfates, citric acid, and sodium citrate were from Fisher Scientific (Pittsburgh, PA). All organic solvents were HPLC-grade and also from Fisher Scientific, including acetonitrile, methanol, and dichloromethane.

\subsection{PFOA degradation experimental setup}

The PFOA degradation experiments were carried out in polypropylene bottles with continuous shake $(120 \mathrm{rpm})$ at $22{ }^{\circ} \mathrm{C}$ in an incubator (Innova 42, New Brunswick Scientific). Each reaction bottle contained $100-\mathrm{mL}$ solution with PFOA initial concentration of 1.00 or $100 \mu$ mole $\mathrm{L}^{-1}$. The solution was prepared in a mineral buffer, a citric buffer, or a solution containing different metal ions $\left(\mathrm{Cu}^{2+}, \mathrm{Mg}^{2+}\right.$, and $\mathrm{Mn}^{2+}$ at 0.1 , 1.0 , or 10 mmole $\mathrm{L}^{-1}$, respectively, or $\mathrm{Fe}^{3+}$ at 0.2 mmole $\mathrm{L}^{-1}$ ) for comparison. The mineral buffer recipe was derived from a formula that has been used for fungal cultivation (Liu et al., 2013) with the concentration of each component reduced 10 times. The major components of the mineral buffer included $\mathrm{CuSO}_{4}, \mathrm{MgSO}_{4}$, and $\mathrm{MnSO}_{4}$. Details for the preparation of each solution were provided in Supplementary Data. The $\mathrm{pH}$ values for the mineral buffer and the citric buffer were both 4.5 . The metal ion solution was prepared without additional $\mathrm{pH}$ buffering, and the determined $\mathrm{pH}$ for each metal ion solution was listed in Table S2 (Supplementary Data). Each reactor also contained 0,20 or $100 \mu$ mole $\mathrm{L}^{-1} \mathrm{HBT}$ and was dosed with $1 \mathrm{U} \mathrm{mL}^{-1}$ laccase to initiate ECOHRs. Every six days during the treatment, the reactor was repeatedly dosed with freshly prepared enzyme stock solution to replenish the laccase activity at $1 \mathrm{U} \mathrm{mL}^{-1}$, 
while at the same time 0,20 or $100 \mu$ mole $\mathrm{L}^{-1}$ of $\mathrm{HBT}$ was also added to the corresponding treatment. Samples without laccase or HBT and a blank control without addition of both were also prepared and processed at the same time with the same volume of HPLC water and acetonitrile supplemented instead of enzyme and HBT stock solution. An additional experiment was conducted to investigate PFOA degradation in ECOHR with the addition of DIPPMPO, a spin trap that can effectively scavenge HBT free radicals. The detail is provided in the Radical Scavenger Experiment in Supplementary Data.

Samples were withdrawn from each reactor at preselected time intervals. For the experiment with initial PFOA nominal concentration of $1.00 \mu$ mole $\mathrm{L}^{-1}\left(0.414 \mathrm{mg} \mathrm{L}^{-1}\right)$, triplicates of $0.5-\mathrm{mL}$ solution were sampled from each reactor and mixed with $0.5 \mathrm{~mL}$ of 0.5- $\mu$ mole $\mathrm{L}^{-1}$ M8PFOA as a surrogate standard. For the experiment with initial PFOA nominal concentration of $100 \mu$ mole $\mathrm{L}^{-1}\left(41.4 \mathrm{mg} \mathrm{L}^{-1}\right)$, triplicates of $0.1-\mathrm{mL}$ samples were taken, and each was diluted with $0.9 \mathrm{~mL}$ HPLC water, from which a $0.1-\mathrm{mL}$ subsample was taken and mixed with $0.5 \mathrm{~mL}$ of 0.5 - $\mu$ mole $\mathrm{L}^{-1}$ M8PFOA. All mixtures were subjected to solid phase extraction cleanup as reported in our previous study (Luo et al., 2015) (a brief description is provided in Supplementary Data) and then analyzed for PFCAs and HBT concentrations described below. The variation of concentrations caused by solution evaporation and the supplement was adjusted by weighing the reaction solution before and after each supplement event. A $20-\mu \mathrm{L}$ solution from each reactor was taken every six days for laccase activity assessment using a method reported previously (Park et al., 1999). One unit of laccase activity is defined as the amount of enzyme that causes one unit change in absorbance at $468 \mathrm{~nm}$ per minute of a DMP solution at $\mathrm{pH} 3.8$ 
in a $1 \mathrm{~cm}$ light path cuvette (Park et al., 1999) (details are included in Supplementary Data).

\subsection{Chemical analysis}

At selective times, $2-\mathrm{mL}$ solution was taken from the reactor $\left(100 \mu\right.$ mole $\mathrm{L}^{-1} \mathrm{PFOA}$ in the mineral buffer) for fluoride analysis. The concentrations of fluoride ion were measured using an ion chromatography (Luo et al., 2015) (a description is provided in Supplementary Data). Quantitative analysis of PFCAs and HBT was performed with a Waters ACQUITY I-Class UPLC system coupled with the XEVO TQD mass spectrometer (Waters, Milford, MA). The separation was carried out on a Waters UPLC BEH C18 column $(2.1 \times 100 \mathrm{~mm}, 1.7 \mu \mathrm{m}$, Waters, Milford, MA $)$ at $40{ }^{\circ} \mathrm{C}$ using a gradient composition of solvent A $\left(5 \mathrm{mmol} \mathrm{L}^{-1}\right.$ ammonium acetate in HPLC water) and solvent $\mathrm{B}\left(5 \mathrm{mmol} \mathrm{L}{ }^{-1}\right.$ ammonium acetate in methanol). The flow rate was $0.3 \mathrm{~mL} \min ^{-1}$ with a gradient program lasting for $10 \mathrm{~min}$ : $0-0.5 \mathrm{~min}$, hold at $10 \% \mathrm{~B}$; $0.5-8 \mathrm{~min}$, linearly increased B from $10 \%$ to $95 \% ; 8-8.1 \mathrm{~min}$, a linear increase from $95 \%$ to $100 \%$; 8.1-9 min, linearly reduced $\mathrm{B}$ to $10 \%$, and then equilibrium at $10 \% \mathrm{~B}$ for $1 \mathrm{~min}$. Electrospray ionization was operated in a negative mode with the parameters set as the capillary voltage at $-1.0 \mathrm{kV}$, desolvation temperature at $400{ }^{\circ} \mathrm{C}$, and source block temperature at $150{ }^{\circ} \mathrm{C}$. Nitrogen (> 99.999\% purity, Airgas) was used as desolvation gas with a flow rate of $550 \mathrm{~L}_{\text {hour }}{ }^{-1}$. PFOA, M8PFOA, HBT, and seven additional PFCAs (C4-C11) were monitored simultaneously using multiple reaction monitoring. The precursor and transition $\mathrm{m} / \mathrm{z}$ values of all the monitored PFCAs and HBT as well as their detection limits are listed in Table S1.

\subsection{Identification of reaction products}


High-resolution mass spectrometry (HRMS) was used to identify reaction products in selected treatments. To this end, a positive control reactor that contained only PFOA without enzyme or HBT addition and a negative control reactor that did not contain PFOA but with repeated enzyme and HBT additions using the same regime as for the treatment reactor were also prepared, processed, and analyzed along with the treatment reactors. At the end of incubation, $1 \mathrm{~mL}$ solution was taken from each reactor and extracted with $1 \mathrm{~mL}$ dichloromethane. The extractant was then reconstituted in $20-\mu \mathrm{L}$ methanol and analyzed using an Orbitrap Elite HRMS (Thermo Scientific, San Jose, U.S.) with the full scan for $\mathrm{m} / z=10$ to 1000 in ESI negative mode (resolution $\mathrm{R}=$ $250,000$ at $m / z 400)$.

By comparing the mass spectra, the $\mathrm{m} / \mathrm{z}$ peaks that were detected in the reaction samples but not in the negative or positive controls were identified as possible products. The element composition of a possible product was assigned by its accurate $\mathrm{m} / \mathrm{z}$ value using a formula generator program (Thermo Xcalibur) with the HRMS mass error range set at $5 \mathrm{ppm}$, and the conventional molecular mass rules, including the carbon-hydrogen ratio and nitrogen rule, were employed to exclude unreasonable element compositions. The structure of a possible product was further deduced from its corresponding fragment ion spectrum $(\mathrm{m} / \mathrm{z}=100$ to 1000$)$ obtained from tandem mass fractionation on the Orbitrap Elite HRMS (resolution $\mathrm{R}=60000$ at $\mathrm{m} / \mathrm{z}$ 400).

\subsection{Differential UV-Vis Spectrometry}

A differential UV-Vis spectrometry method (Yan et al., 2015) was used to probe possible interactions between metal ions and PFOA. To this end, a 2-mmole $\mathrm{L}^{-1}$ metal $\left(\mathrm{Cu}^{2+}, \mathrm{Mg}^{2+}\right.$ or $\left.\mathrm{Mn}^{2+}\right)$ ion solution was mixed with a $2-m m o l e \mathrm{~L}^{-1}$ PFOA solution by 
different ratios ranging from 9:1 to 1:9 to make $10-\mathrm{mL}$ mixture solutions. An additional $15-\mathrm{mL}$ citric buffer solution with the $\mathrm{pH}$ equals to the solution of each ion at 10 mmole $\mathrm{L}^{-}$ ${ }^{1}$ (4.9 for $\mathrm{Cu}^{2+}, 7.0$ for $\mathrm{Mg}^{2+}$, and 6.5 for $\mathrm{Mn}^{2+}$ ) was added to the corresponding mixture. The combinations of the metal ion and the PFOA molar concentrations were maintained at $0.8 \mathrm{mmole}^{-1}$ for all final mixtures. Additional reference solutions without metal ion or PFOA were also prepared in the same manner. The $\mathrm{Fe}^{3+}$-PFOA mixtures were prepared in the same way as above, except that the mixture solutions were prepared with 0.5 mmole $\mathrm{L}^{-1} \mathrm{Fe}^{3+}$ and 0.5 mmole $\mathrm{L}^{-1} \mathrm{PFOA}$ solutions at $\mathrm{pH} 2.9$, and the final combined

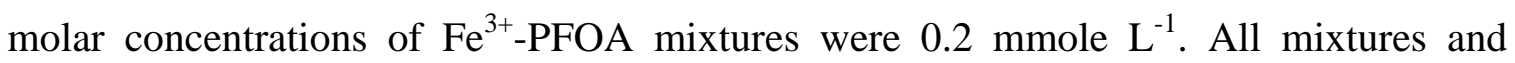
reference solutions were allowed to equilibrate for 24 hours prior to being scanned on a Beckman DU800 spectrophotometer for absorbance spectra at wavelengths from 200 to $800 \mathrm{~nm}$. A differential absorbance spectrum (DAS) was constructed by the following equation:

$$
\Delta \mathrm{A}_{\lambda, \text { DAS }}=\mathrm{A}_{\lambda, \text { mixture }}-\mathrm{A}_{\lambda, \text { PFOA }}-\mathrm{A}_{\lambda, \text { cation }}
$$

where $A_{\lambda}$, mixture, $A_{\lambda, \text { PFOA }}$ and $A_{\lambda \text {, cation }}$ are the absorbance at $\lambda$ wavelength of the mixture solution, and the corresponding reference PFOA and metal ion solution, respectively.

\subsection{Statistic analysis}

A general linear model ANOVA with significant differences $(\mathrm{P}=0.05)$ test was conducted on SAS followed by a least significant difference test to compare the PFOA and HBT concentrations of the same treatment over different sampling times as well as the different treatments at the same sampling time. 


\section{Results and discussion}

\subsection{Rate of PFOA removal during ECOHRs}

Fig. 1 depicts the change of PFOA concentration over time in a laccase-HBT reaction system in the mineral buffer, with PFOA initial nominal concentrations of 1.00 or 100 $\mu$ mole $\mathrm{L}^{-1}$, respectively. For both treatments, PFOA concentrations remained stable in the systems with the addition of only $1 \mathrm{U} \mathrm{mL}^{-1}$ of laccase but no mediator, which were essentially no different from the blank control system to which both enzyme and HBT were not added. PFOA degradation was evident when both laccase and HBT were added repetitively. For $1.00 \mu$ mole $\mathrm{L}^{-1}$ initial PFOA treatment, PFOA removal was $45.7 \pm$ $2.13 \%$ after 156 days with repeated dosing of $1 \mathrm{U} \mathrm{mL}^{-1}$ laccase and $20 \mu$ mole $\mathrm{L}^{-1} \mathrm{HBT}$ (named as 1-20 in Fig. 1a). Similar degradation was observed for $100 \mu$ mole $\mathrm{L}^{-1}$ PFOA with $46.8 \pm 2.20 \%$ PFOA degraded after 156 days (Fig. 1b). The PFOA degradation data in Fig. 1 were fitted well to the pseudo-first-order rate model (Fig. S1). The reaction rate constants $(k)$ for $1.00 \mu$ mole $L^{-1}$ PFOA $\left(0.0042\right.$ day $\left.^{-1}, \mathrm{r}^{2}=0.86\right)$ and $100 \mu$ mole $\mathrm{L}^{-1}$ $\left(0.0040\right.$ day $\left.^{-1}, \mathrm{r}^{2}=0.98\right)$ systems in the $1-20$ treatment were similar to each other. This result suggests that the reaction rate is not limited by the increase of PFOA initial concentration, which has ramification in potential application of ECOHRs for PFOA remediation. Table S3 in the Supplementary Data has summarized the PFOA degradation data in all conditions that we have tested in the current study. The laccase-catalyzed PFOA degradation rates reported in this study were generally slower than the ones reported for a broad spectrum of emerging contaminants (Nguyen et al., 2015; Nguyen et al., 2014a; Nguyen et al., 2014b). Given the extremely high energy carbon-fluorine bond $\left(531.5 \mathrm{~kJ} \mathrm{~mol}^{-1}\right)$ and the strong shielding effect of the helical conformation of PFOA 
molecule (Torres et al., 2009), such slow reaction rates were not unexpected. However, compared to the reported half-life of 41years in natural water (Lindstrom et al., 2011), the half-life of PFOA in ECOHR was approximately 157 days in this study, thus showing a potential of ECOHR to enhance the degradation of PFOA in water environment.

\subsection{Effect of mediator concentration}

For the experiment with PFOA initial concentration at $100 \mu \mathrm{mole} \mathrm{L}^{-1}$, ECOHRs was tested with HBT at two different dosages $\left(20\right.$ and $100 \mu$ mole $\left.\mathrm{L}^{-1}\right)$ under otherwise the same conditions, which are respectively specified as 1-20 or 1-100 treatment in Fig. 1 b. PFOA removal was $46.8 \pm 2.20 \%$ in the 1-20 treatment while that for the 1-100 treatment was $37.9 \pm 6.24 \%$ at day 156 . The pseudo-first order reaction rate constant $(k)$ was 0.0040 day $^{-1}\left(r^{2}=0.98\right)$ and 0.0030 day $^{-1}\left(r^{2}=0.93\right)$ for $1-20$ and 1-100 treatment, respectively. The HBT conversion over the reaction period was also quantified (Fig. S2a, Supplementary Data). These data indicate that, although about four times of HBT has been converted by laccase in the 1-100 treatment $(201 \mu$ mole $)$ than in the 1-20 treatment (51.7 $\mu$ mole), the increase of HBT dosage did not necessarily enhance the chance of BTNO to attack and react with PFOA. Instead, the production of excessive BTNO may stimulate radical quenching pathways and thus mitigate PFOA degradation (Colosi et al., 2006). An additional test was carried out with PFOA and HBT but without laccase. No change of PFOA concentration can be observed (0\%) after 48 days of incubation, while 27\% PFOA was removed in the treatment with both laccase and HBT present on day 48 (Fig. 1b). The result further confirmed that HBT itself could not initiate PFOA degradation and laccase is essential to PFOA degradation. 
The laccase activities in the reaction solutions were also monitored during the incubation period, and are shown in Fig. S2b (Supplementary Data). It is evident that laccase deactivated more rapidly in the systems with higher HBT concentration, in the order $1-100>1-20>1-0$ treatment. This is reasonable because the radicals generated from the active substrates of an ECOHR enzyme can deactivate the enzyme, known as a suicide mechanism (Huang et al., 2005). Therefore, the balance between laccase stability and the productivity of BTNO governs the efficiency of ECOHRs in these systems. Based on the data, the $1 \mathrm{U} \mathrm{mL}^{-1}$ laccase and $20 \mu$ mole $\mathrm{L}^{-1} \mathrm{HBT}$ combination offered the highest PFOA removal.

\subsection{Impact of metal ions on PFOA degradation}

An intriguing observation was made in this study, in which the PFOA removal occurring in the mineral buffer $(\mathrm{pH} 4.5)$ as shown in Fig. 1a was not evident in a citric buffer solution ( $\mathrm{pH} 4.5)$ as seen in Fig. S3 under otherwise the same reaction conditions. Apparently, the compositions of the buffer solutions had significant influence in the reaction rates. Likely, the metal ions included in the mineral buffer solution, 1.60 mmole $\mathrm{L}^{-1} \mathrm{Cu}^{2+}, 0.203$ mmole $\mathrm{L}^{-1} \mathrm{Mg}^{2+}$, and 0.002 mmole $\mathrm{L}^{-1} \mathrm{Mn}^{2+}$, may play an important role in facilitating PFOA degradation in ECOHRs.

We then evaluated PFOA degradation in a series of solutions that each contained an individual metal ion, $\mathrm{Cu}^{2+}, \mathrm{Mg}^{2+}$ or $\mathrm{Mn}^{2+}$, at different concentrations under the same laccase and HBT regime as the 1-20 treatment in the mineral buffer solution (Fig.2 and Fig. S4). As shown in Fig. 2a and Fig. S4a, PFOA degradation was evident in the

presence of $\mathrm{Cu}^{2+}$, and it increased with the increase of $\mathrm{Cu}^{2+}$ concentration. The determined pseudo-first order reaction rate constant was 0.0040 day $^{-1}\left(r^{2}=0.88\right), 0.0025$ 
$\operatorname{day}^{-1}\left(\mathrm{r}^{2}=0.92\right)$, and $0.0001 \mathrm{day}^{-1}\left(\mathrm{r}^{2}=0.014\right)$ for 10,1 and $0.1 \mathrm{mmole}^{-1} \mathrm{Cu}^{2+}$ treatment, respectively (Fig. S5a). Little, if any, PFOA degradation was observed in the $\mathrm{Mg}^{2+}$ or $\mathrm{Mn}^{2+}$ solutions regardless of their concentrations (Fig. 2b and 2c; Fig. S4b and 4c) (see Fig. S6 for statistical analysis results). An earlier photochemical degradation study also showed that $\mathrm{Cu}^{2+}$ enhanced PFOA degradation more than $\mathrm{Mg}^{2+}$ and $\mathrm{Mn}^{2+}$ ions (Wang et al., 2008).

Several earlier studies have indicated that the presence of metal ions such as $\mathrm{Fe}^{3+}$ enhanced the photolytic decomposition of PFCAs (Hori et al., 2007; Tang et al., 2012; Wang et al., 2008). We therefore further tested PFOA degradation in ECOHRs system with the presence of ferric ion (Fig. 3). Continuous degradation of PFOA was observed, and it followed the pseudo-first order kinetics with a reaction rate constant of $k=0.0032$ day ${ }^{-1}, r^{2}=0.82$ (Fig. S5b) in the 1-20 treatment system in a solution containing $\mathrm{Fe}^{3+}$ of 0.2 mmole L $^{-1}$. PFOA removal reached $35.0 \pm 4.89 \%$ after 108 days of incubation, which is similar to that in the mineral buffer ( $38.3 \pm 3.90 \%$ after 114 days $)$.

An important factor that could influence PFOA degradation during ECOHRs is the laccase activity. To verify this, the change of laccase activity in each ECOHRs system with the presence of an individual metal ion was monitored. The laccase activity seems less stable when the cation concentration was higher, as indicated by the more rapid laccase deactivation trends during every six days of the enzyme addition cycle (Fig. S7). Laccase stabilities were similar among the three cation species at 0.1 -mmole $\mathrm{L}^{-1}$ level, while, in both 1.0 and 10 -mmole $\mathrm{L}^{-1}$ solutions, the stability followed the order $\mathrm{Mg}^{2+}$ > $\mathrm{Mn}^{2+}>\mathrm{Cu}^{2+}$. Although laccase is the least stable in the $10-\mathrm{mmole}^{-1} \mathrm{Cu}^{2+}$ solution, the degradation of PFOA was the most prominent in this system (Fig. 2), suggesting that 
enzyme activity may not be the factor controlling PFOA degradation rate in these systems. Instead, the laccase-HBT interaction appears to be the essential factor controlling PFOA degradation during ECOHRs. This was confirmed by a radical scavenger experiment (Fig. S8). In the samples with the addition of $200 \mu$ mole $^{-1}$ of DIPPMPO which is an effective BTNO scavenger (Zoia and Argyropoulos, 2010), PFOA concentration showed no significantly change over time with the presence of both $1 \mathrm{U}$ $\mathrm{mL}^{-1}$ laccase and $20 \mu$ mole $\mathrm{L}^{-1} \mathrm{HBT}$, while $40 \%$ degradation of PFOA was obtained in the 1-20 treatment without the addition of DIPPMPO (Fig. S8). These results strongly corroborate the key role of laccase-produced BTNO, whose concentrations were regulated by the interaction between laccase and $\mathrm{HBT}$ in ECOHR.

In addition to laccase and HBT, the ECOHR systems containing different cation species at varying concentrations may impact HBT conversion, generating BTNO at different efficiency and thus causing the disparity in PFOA degradation rate. HBT conversion in these systems was also monitored and the results are presented in Fig. 4. It is noted that over $98 \%$ conversion of the total added HBT ( $40 \mu$ mole) was achieved in all systems, although the slight difference was detected among systems having different cation species. In particular, the systems with $\mathrm{Cu}^{2+}$ concentrations at three different levels exhibited no significant difference in HBT conversion (Fig. 4), while the PFOA degradation efficiency increased with the increase of $\mathrm{Cu}^{2+}$ concentration (Fig. 2a). This indicates that the effect of cations on PFOA degradation was not via a mechanism by impacting HBT conversion and BTNO generation.

An earlier study revealed that the formation of a complex between $\mathrm{Fe}^{3+}$ and PFOA facilitated the photodegradation of PFOA (Wang et al., 2008). We then hypothesized that 
the metal ions that facilitate PFOA degradation in the ECOHR systems was related to their charge interactions with PFOA and the enzyme. Both PFOA (pKa -0.5) (Goss, 2008) and laccase (pI 3.0) (Mansur et al., 2003) were negatively charged in all examined conditions. They thus repulse each other due to the electrostatic force. Meanwhile, the short lifespan of BTNO (Bourbonnais et al., 1998; Colosi et al., 2006) limited its chance of reaching PFOA after being released from the enzyme. It is possible that certain divalent cations, such as $\mathrm{Cu}^{2+}$, can bridge negatively charged PFOA and laccase by forming complexes, which enabled the BTNO released from laccase to attack PFOA.

We further assessed the interactions between PFOA and metal ions using the differential absorption spectrometry (DAS) (Yan et al., 2013; Yan et al., 2015) as described in the experimental section. The DAS of $\mathrm{Mg}^{2+}-\mathrm{PFOA}$ and $\mathrm{Mn}^{2+}-\mathrm{PFOA}$ (Fig. 5b and Fig. 5c) did not have any distinct peak at the wavelength ranged from 220 to $400 \mathrm{~nm}$. However, the $\mathrm{Cu}^{2+}$-PFOA and $\mathrm{Fe}^{3+}$-PFOA DAS had an intensive negative peak at 265 and $239 \mathrm{~nm}$, respectively which varied as a function of the component ratio (Fig. 5a and 5d). The negative peak with such variation suggested the change of electronic density in the molecules caused by the formation of a complex between $\mathrm{Cu}^{2+} / \mathrm{Fe}^{3+}$ and PFOA (Yan and Korshin, 2014; Yan et al., 2015). Wang et al. (2008) also indirectly confirm the formation of a complex between $\mathrm{Fe}^{3+}$ and PFOA by showing the change of UV-Vis absorption spectra after mixing $\mathrm{Fe}^{3+}$ with PFOA. The solution $\mathrm{pH}$ may also play a role in the formation of complex between the multivalent metal ion and PFOA. Nonetheless, the result supports the notion that a multivalent metal ion (e.g. $\mathrm{Cu}^{2+}$ and $\mathrm{Fe}^{3+}$ ) that complexes with PFOA may facilitate PFOA degradation; while metals (e.g. $\mathrm{Mg}^{2+}$ and $\mathrm{Mn}^{2+}$ ) that do not complex with PFOA at the examined conditions has no impact on PFOA degradation. 


\subsection{PFOA degradation products}

The concentration of fluoride was quantified using ion chromatography in the ECOHR samples with PFOA initial concentration at $100 \mu$ mole $^{-1}$ in the mineral buffer (Fig. 6). It shows that the fluoride concentration increased along with PFOA degradation in both 1-20 and 1-100 treatment samples. At day 42, the fluoride concentration in 1-100 treatment $\left(0.199 \mu\right.$ mole $\left.\mathrm{L}^{-1}\right)$ was nearly twice of that in 1-20 treatment $\left(0.105 \mu\right.$ mole $\left.\mathrm{L}^{-1}\right)$ which corresponds to the PFOA removal of $20.3 \%$ and $12.4 \%$ respectively. After 96 days of incubation, the PFOA removal in 1-20 treatment (30.5\%) caught up with 1-100 treatment (34.1\%) while the fluoride concentrations in these two samples also reached a similar level (0.205 and $0.250 \mu$ mole $\mathrm{L}^{-1}$ respectively). The corresponding defluorination ratios (R) at 96 -day were $44.8 \%$ and $48.9 \%$ for $1-20$ and $1-100$ treatment respectively calculated according to the equation of $R=\frac{C_{F^{-}}}{\left(C_{0}-C_{t}\right) \times 15}$ (Lin et al., 2012).

Possible degradation products were also identified using HRMS in 1-20 samples with $100 \mu$ mole $\mathrm{L}^{-1} \mathrm{PFOA}$ in the mineral buffer and $1.00 \mu$ mole $\mathrm{L}^{-1} \mathrm{PFOA}$ in the 10 -mmole $\mathrm{L}^{-}$ ${ }^{1} \mathrm{Cu}^{2+}$ solution. A total of 10 products were identified (Table 1 ). Six of the products were found in the mineral buffer while four were detected in the $10-\mathrm{mmole}^{-1} \mathrm{Cu}^{2+}$ solution. The molecular structures were deduced from elemental composition determined by the accurate mass of the molecular ion $(<5 \mathrm{ppm})$ and the fragment ion spectra from tandem mass spectrometry. All fragment ion spectra of degradation products were summarized in Supplementary Data Fig. S9, S10 and S11.

All tentative product candidates identified in this study (Table 1) are partially fluorinated or contain perfluoroalkyl moieties, which are similar to those identified in the earlier study (Luo et al., 2015), although are not of exactly the same structures. Such 
products were likely formed from a combination of free radical rearrangement and crosscoupling processes. Namely, the reaction is initiated by transferring an electron from PFOA to BTNO followed by Kolbe decarboxylation cycles and/or radical rearrangements to form shorter-chain perfluoroalkyl radicals, including ones with double bonds. The BTNO do not only initiate PFOA decarboxylation but also convert other non-fluorinated organic chemicals in the solution to free radicals, which then cross-couple with the perfluoroalkyl radicals to form the products (Table 1) that are either partially fluorinated or contain a perfluoroalkyl moiety. Alternatively, the BTNO radicals or the other organic free radicals derived from BTNO reactions may in turn attack the $\mathrm{C}-\mathrm{C}$ bonds in PFOA, leading to the substitution products. It is worth noting that the molecular structures of products No. 4, 6 and 7 contained HBT moieties (Table 1; Supplementary Data Fig. S9, S10 and S11). This is a direct evidence of cross-coupling between BTNO and PFOAderived perfluoroalkyl radicals. This kind of structure was not found in the earlier study (Luo et al. 2015), probably due to the much lower PFOA concentration (1.00 $\mu$ mole $\mathrm{L}^{-1}$ ) used in that study.

\section{Conclusion}

This study examined the key factors that control the degradation of PFOA during laccase-induced ECOHRs. PFOA degradation followed the pseudo-first-order kinetics with reaction rate constants ranged from 0.0025 to 0.0044 day $^{-1}$ depending on the conditions. PFOA initial concentration did not significantly impact the PFOA degradation rate; while the laccase activity and HBT concentration seem to interactively regulate PFOA degradation. An important finding is that multivalent metal ions played a

critical role, and the presence of certain ions (e.g. $\mathrm{Cu}^{2+}$ and $\mathrm{Fe}^{3+}$ ) that can form 
complexwith PFOA at the examined conditions is essential for PFOA degradation during ECOHRs. It is probably because these multivalent metal ions can bridge the negatively charged PFOA and laccase together, therefore facilitating PFOA degradation.

The detection of the continuous release of fluoride and formation of partially fluorinated compounds in the reaction solution confirmed PFOA degradation during ECOHRs, and verified the pathway involving BTNO-initiated radical decarboxylation, rearrangement, and cross-coupling, although the products detectable may vary depending on reaction conditions, such as PFOA initial concentration and incubation time.

\section{Acknowledgements}

The study was supported in part by U.S. Department of Defense SERDP ER-2127, W912HQ-11-C-0022 and the U.S. Air Force Civil Engineering Center BAA Project FA8903-12-C-0005. JL acknowledges the support from NSFC 51178224. We thank Dr. Dennis R. Phillips and Dr. Chau-wen Chou at the University of Georgia Proteomic and Mass Spectrometry Core Facility for help with the high resolution mass spectrometry analysis.

\section{Supplementary Data}

Additional experimental details, figures, and table are available. 


\section{References}

Ahrens, L., 2011. Polyfluoroalkyl compounds in the aquatic environment: a review of their occurrence and fate. Journal of Environmental Monitoring 13, 20-31.

Armitage, J., Cousins, I.T., Buck, R.C., Prevedouros, K., Russell, M.H., MacLeod, M., Korzeniowski, S.H., 2006. Modeling Global-Scale Fate and Transport of Perfluorooctanoate Emitted from Direct Sources. Environmental Science \& Technology 40, 6969-6975.

Backe, W.J., Field, J.A., Day, T.C., 2013. Zwitterionic, Cationic, and Anionic Fluorinated Chemicals in Aqueous Film Forming Foam (AFFF) Formulations and Groundwater from U.S. Military Bases by Non-Aqueous Large-Volume Injection HPLC-MS/MS. Environmental Science \& Technology.

Benskin, J.P., Muir, D.C.G., Scott, B.F., Spencer, C., De Silva, A.O., Kylin, H., Martin, J.W., Morris, A., Lohmann, R., Tomy, G., Rosenberg, B., Taniyasu, S., Yamashita, N., 2012.

Perfluoroalkyl Acids in the Atlantic and Canadian Arctic Oceans. Environmental Science \& Technology 46, 5815-5823.

Bourbonnais, R., Leech, D., Paice, M.G., 1998. Electrochemical analysis of the interactions of laccase mediators with lignin model compounds. Biochimica et Biophysica Acta (BBA) - General Subjects 1379, 381-390.

Cañas, A.I., Alcalde, M., Plou, F., Martínez, M.J., Martínez, Á.T., Camarero, S., 2007.

Transformation of Polycyclic Aromatic Hydrocarbons by Laccase Is Strongly Enhanced by Phenolic Compounds Present in Soil. Environmental Science \& Technology 41, 2964-2971.

Colosi, L.M., Burlingame, D.J., Huang, Q., Weber, W.J., 2006. Peroxidase-Mediated Removal of a Polychlorinated Biphenyl Using Natural Organic Matter as the Sole Cosubstrate. Environ. Sci. Technol. 41, 891-896.

Colosi, L.M., Pinto, R.A., Huang, Q., Weber, W.J., Jr., 2009. Peroxidase-mediated degradation of perfluorooctanoic acid. Environmental Toxicology and Chemistry 28, 264-271.

Du, X., Li, J., Gellerstedt, G., Rencoret, J., Del Río, J.C., Martínez, A.T., Gutiérrez, A., 2013. Understanding Pulp Delignification by Laccase-Mediator Systems through Isolation and Characterization of Lignin-Carbohydrate Complexes. Biomacromolecules 14, 3073-3080.

EFSA, 2008. Opinion of the Scientific Panel on Contaminants in the Food chain on Perfluorooctane sulfonate (PFOS), perfluorooctanoic acid (PFOA) and their salts. The EFSA Journal.

Gatto, S., Sansotera, M., Persico, F., Gola, M., Pirola, C., Panzeri, W., Navarrini, W., Bianchi, C.L., 2015. Surface fluorination on $\mathrm{TiO} 2$ catalyst induced by photodegradation of perfluorooctanoic acid. Catalysis Today 241, 8-14.

Goss, K.-U., 2008. The pKa Values of PFOA and Other Highly Fluorinated Carboxylic Acids. Environmental Science \& Technology 42, 456-458. 
Guggenberger, G., 2005. Humification and Mineralization in Soils, in: Varma, A., Buscot, F. (Eds.), Microorganisms in Soils: Roles in Genesis and Functions. Springer Berlin Heidelberg, pp. 85-106.

Guo, J., Resnick, P., Efimenko, K., Genzer, J., DeSimone, J.M., 2008. Alternative Fluoropolymers to Avoid the Challenges Associated with Perfluorooctanoic Acid. Industrial \& Engineering Chemistry Research 47, 502-508.

Hori, H., Yamamoto, A., Koike, K., Kutsuna, S., Osaka, I., Arakawa, R., 2007. Photochemical decomposition of environmentally persistent short-chain perfluorocarboxylic acids in water mediated by iron(II)/(III) redox reactions. Chemosphere 68, 572-578.

Huang, Q., Huang, Q., Pinto, R.A., Griebenow, K., Schweitzer-Stenner, R., Weber, W.J., 2005. Inactivation of Horseradish Peroxidase by Phenoxyl Radical Attack. Journal of the American Chemical Society 127, 1431-1437.

Johannes, C., Majcherczyk, A., 2000. Natural Mediators in the Oxidation of Polycyclic Aromatic Hydrocarbons by Laccase Mediator Systems. Applied and Environmental Microbiology 66, 524528.

Kärrman, A., Elgh-Dalgren, K., Lafossas, C., Møskeland, T., 2011. Environmental levels and distribution of structural isomers of perfluoroalkyl acids after aqueous fire-fighting foam (AFFF) contamination. Environmental Chemistry 8, 372-380.

Keum, Y.S., Li, Q.X., 2004. Fungal laccase-catalyzed degradation of hydroxy polychlorinated biphenyls. Chemosphere 56, 23-30.

Lau, C., Anitole, K., Hodes, C., Lai, D., Pfahles-Hutchens, A., Seed, J., 2007. Perfluoroalkyl Acids: A Review of Monitoring and Toxicological Findings. Toxicological Sciences 99, 366-394.

Lin, H., Niu, J., Ding, S., Zhang, L., 2012. Electrochemical degradation of perfluorooctanoic acid (PFOA) by Ti/SnO2-Sb, Ti/SnO2-Sb/PbO2 and Ti/SnO2-Sb/MnO2 anodes. Water Research 46, 2281-2289.

Lin, J.C., Lo, S.L., Hu, C.Y., Lee, Y.C., Kuo, J., 2015. Enhanced sonochemical degradation of perfluorooctanoic acid by sulfate ions. Ultrasonics Sonochemistry 22, 542-547.

Lindstrom, A.B., Strynar, M.J., Libelo, E.L., 2011. Polyfluorinated Compounds: Past, Present, and Future. Environmental Science \& Technology 45, 7954-7961.

Liu, J., Cai, Y., Liao, X., Huang, Q., Hao, Z., Hu, M., Zhang, D., Li, Z., 2013. Efficiency of laccase production in a $65-\mathrm{L}$ air-lift reactor for potential green industrial and environmental application. Journal of Cleaner Production 39, 154-160.

Luo, Q., Lu, J., Zhang, H., Wang, Z., Feng, M., Chiang, S.-Y.D., Woodward, D., Huang, Q., 2015. Laccase-Catalyzed Degradation of Perfluorooctanoic Acid. Environmental Science \& Technology Letters 2, 198-203.

Mansur, M., Arias, M.E., Copa-Patiño, J.L., Flärdh, M., González, A.E., 2003. The white-rot fungus Pleurotus ostreatus secretes laccase isozymes with different substrate specificities. Mycologia 95, 1013-1020. 
Nguyen, L.N., Hai, F.I., Price, W.E., Kang, J., Leusch, F.D.L., Roddick, F., van de Merwe, J.P., Magram, S.F., Nghiem, L.D., 2015. Degradation of a broad spectrum of trace organic contaminants by an enzymatic membrane reactor: Complementary role of membrane retention and enzymatic degradation. International Biodeterioration \& Biodegradation 99, 115-122.

Nguyen, L.N., Hai, F.I., Price, W.E., Leusch, F.D.L., Roddick, F., Ngo, H.H., Guo, W., Magram, S.F., Nghiem, L.D., 2014a. The effects of mediator and granular activated carbon addition on degradation of trace organic contaminants by an enzymatic membrane reactor. Bioresource Technology 167, 169-177.

Nguyen, L.N., Hai, F.I., Yang, S., Kang, J., Leusch, F.D.L., Roddick, F., Price, W.E., Nghiem, L.D., 2014b. Removal of pharmaceuticals, steroid hormones, phytoestrogens, UV-filters, industrial chemicals and pesticides by Trametes versicolor: Role of biosorption and biodegradation. International Biodeterioration \& Biodegradation 88, 169-175.

O'Hagan, D., 2008. Understanding organofluorine chemistry. An introduction to the C-F bond. Chemical Society Reviews 37, 308-319.

Park, J.-W., Dec, J., Kim, J.-E., Bollag, J.-M., 1999. Effect of Humic Constituents on the Transformation of Chlorinated Phenols and Anilines in the Presence of Oxidoreductive Enzymes or Birnessite. Environmental Science \& Technology 33, 2028-2034.

Paul, A.G., Jones, K.C., Sweetman, A.J., 2008. A First Global Production, Emission, And Environmental Inventory For Perfluorooctane Sulfonate. Environmental Science \& Technology 43, 386-392.

Piccolo, A., Cozzolino, A., Conte, P., Spaccini, R., 2000. Polymerization of humic substances by an enzyme-catalyzed oxidative coupling. Naturwissenschaften 87, 391-394.

Prevedouros, K., Cousins, I.T., Buck, R.C., Korzeniowski, S.H., 2006. Sources, Fate and Transport of Perfluorocarboxylates. Environmental Science \& Technology 40, 32-44.

Renner, R., 2001. Growing Concern Over Perfluorinated Chemicals. Environmental Science \& Technology 35, 154A-160A.

Ruan, T., Lin, Y., Wang, T., Jiang, G., Wang, N., 2015. Methodology for studying biotransformation of polyfluoroalkyl precursors in the environment. TrAC Trends in Analytical Chemistry 67, 167-178.

Spachmo, B., Arukwe, A., 2012. Endocrine and developmental effects in Atlantic salmon (Salmo salar) exposed to perfluorooctane sulfonic or perfluorooctane carboxylic acids. Aquatic Toxicology 108, 112-124.

Tang, H., Xiang, Q., Lei, M., Yan, J., Zhu, L., Zou, J., 2012. Efficient degradation of perfluorooctanoic acid by UV-Fenton process. Chemical Engineering Journal 184, 156-162.

Torres, F.J., Ochoa-Herrera, V., Blowers, P., Sierra-Alvarez, R., 2009. Ab initio study of the structural, electronic, and thermodynamic properties of linear perfluorooctane sulfonate (PFOS) and its branched isomers. Chemosphere 76, 1143-1149. 
Wang, Y., Zhang, P., Pan, G., Chen, H., 2008. Ferric ion mediated photochemical decomposition of perfluorooctanoic acid (PFOA) by $254 \mathrm{~nm}$ UV light. Journal of Hazardous Materials 160, 181186.

Woolridge, E., 2014. Mixed Enzyme Systems for Delignification of Lignocellulosic Biomass. Catalysts $4,1$.

Yan, M., Dryer, D., Korshin, G.V., Benedetti, M.F., 2013. In situ study of binding of copper by fulvic acid: Comparison of differential absorbance data and model predictions. Water Research 47, 588-596.

Yan, M., Korshin, G.V., 2014. Comparative Examination of Effects of Binding of Different Metals on Chromophores of Dissolved Organic Matter. Environmental Science \& Technology 48, 3177-3185.

Yan, M., Lu, Y., Gao, Y., Benedetti, M.F., Korshin, G.V., 2015. In-Situ Investigation of Interactions between Magnesium Ion and Natural Organic Matter. Environmental Science \& Technology 49, 8323-8329.

Zoia, L., Argyropoulos, D.S., 2010. Detection of ketyl radicals using 31P NMR spin trapping. Journal of Physical Organic Chemistry 23, 505-512. 

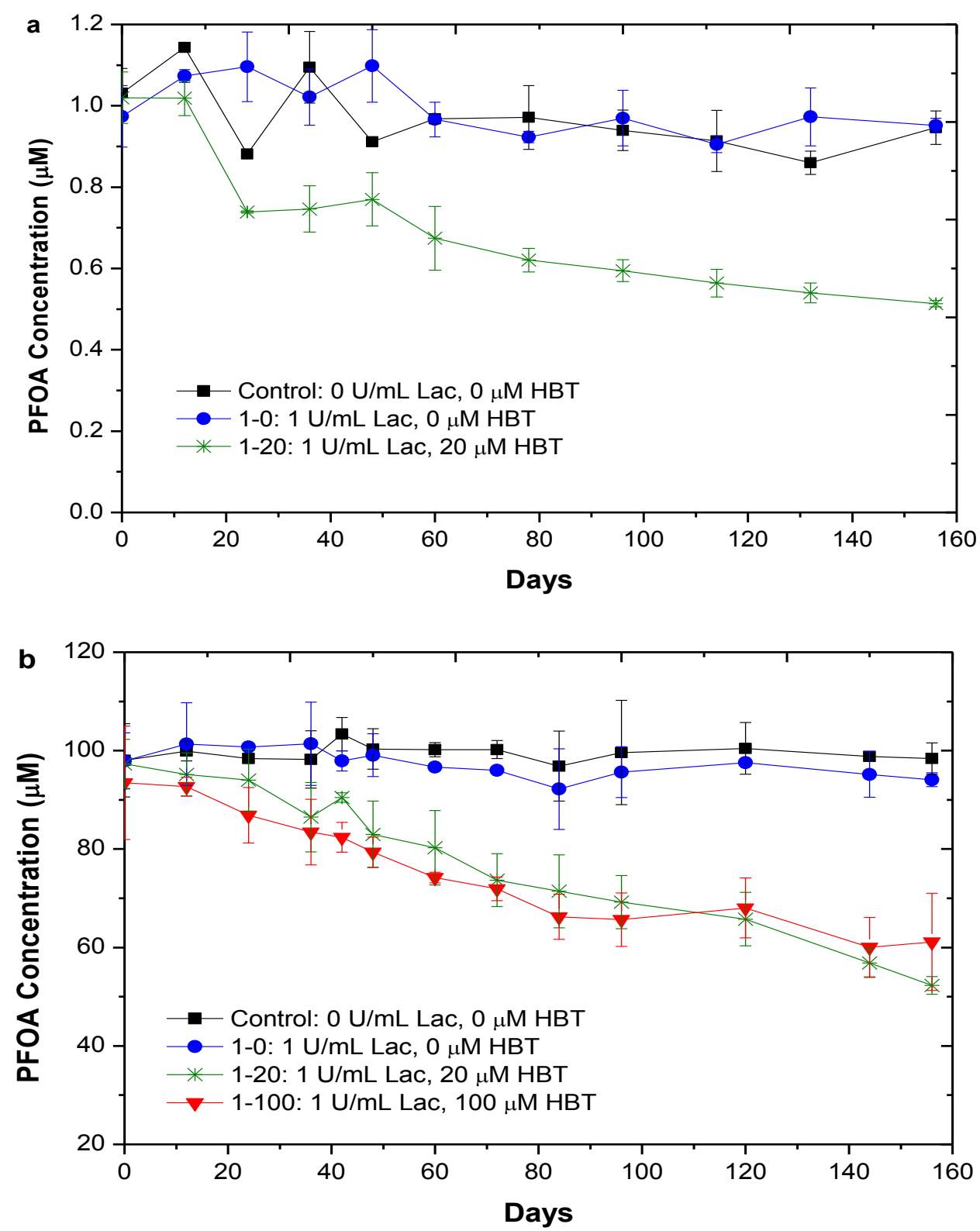

Fig. 1. Change of PFOA concentration during laccase-mediated ECOHRs in the mineral buffer. (a) PFOA initial concentration of $1.00 \mu$ mole $^{-1}$; (b) PFOA initial concentration of $100 \mu$ mole $\mathrm{L}^{-1}$. Control: the positive control to which no laccase or HBT was added; 10: $1 \mathrm{U} \mathrm{mL}^{-1}$ laccase added every $6 \mathrm{~d}$ but no HBT; $1-20: 1 \mathrm{U} \mathrm{mL}^{-1}$ laccase and $20 \mu$ mole $\mathrm{L}^{-1}$ HBT added every $6 \mathrm{~d}$; 1-100: $1 \mathrm{U} \mathrm{mL}^{-1}$ laccase and $100 \mu$ mole $\mathrm{L}^{-1} \mathrm{HBT}$ added every $6 \mathrm{~d}$. The error bars denote the standard deviation of three replicates. 


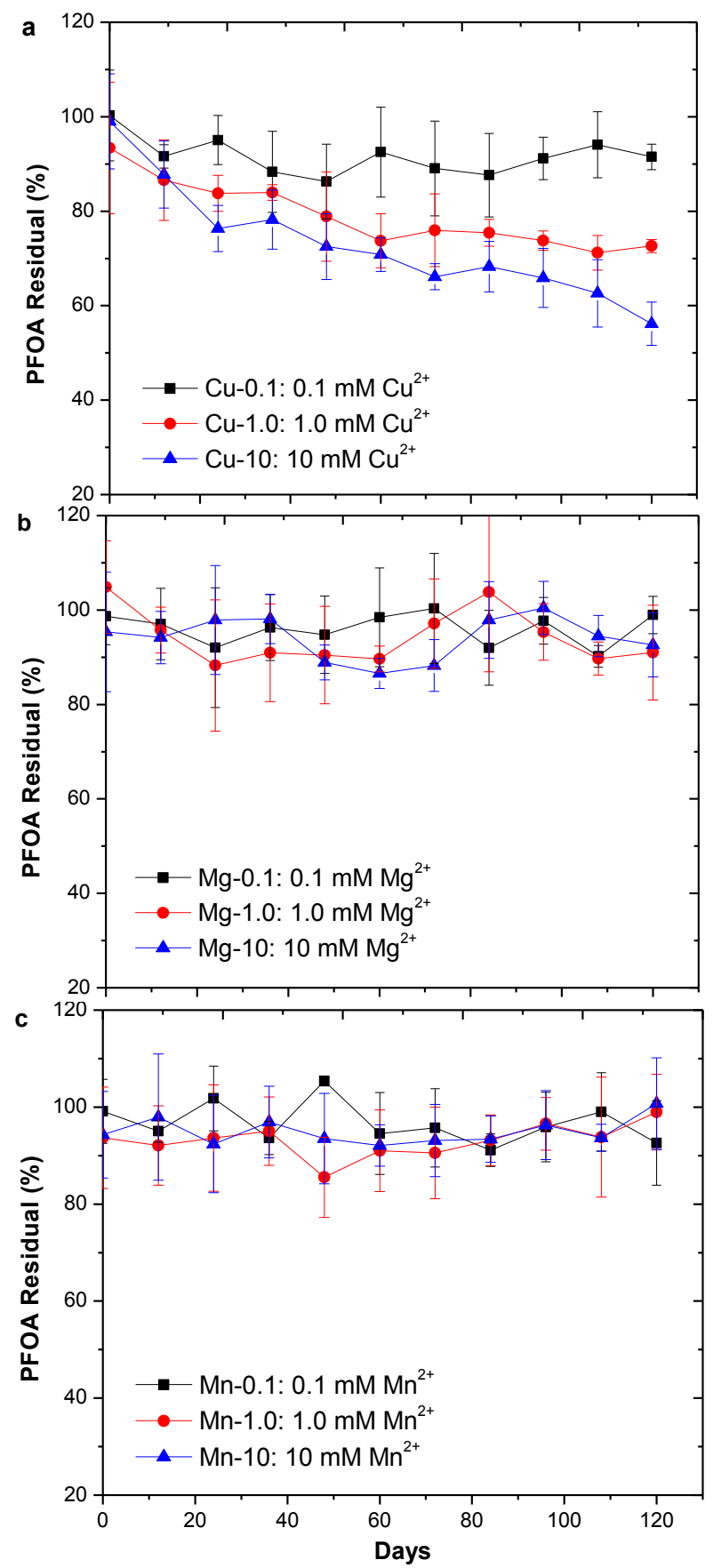

Fig. 2. Change of PFOA residual in $1 \mathrm{U} \mathrm{mL}^{-1}$ laccase and $20 \mu$ mole $\mathrm{L}^{-1} \mathrm{HBT}$ induced ECOHRs over time with the presence of $0.1 / 1.0 / 10$ mmole $\mathrm{L}^{-1}$ cations: (a) $\mathrm{Cu}^{2+}$; (b) $\mathrm{Mg}^{2+}$; and (c) $\mathrm{Mn}^{2+}$. The PFOA residual is calculated by dividing the PFOA concentration in the reaction sample by that in the control (without laccase or HBT) sampled at the same time. The error bars denote the standard deviation of three replicates. 


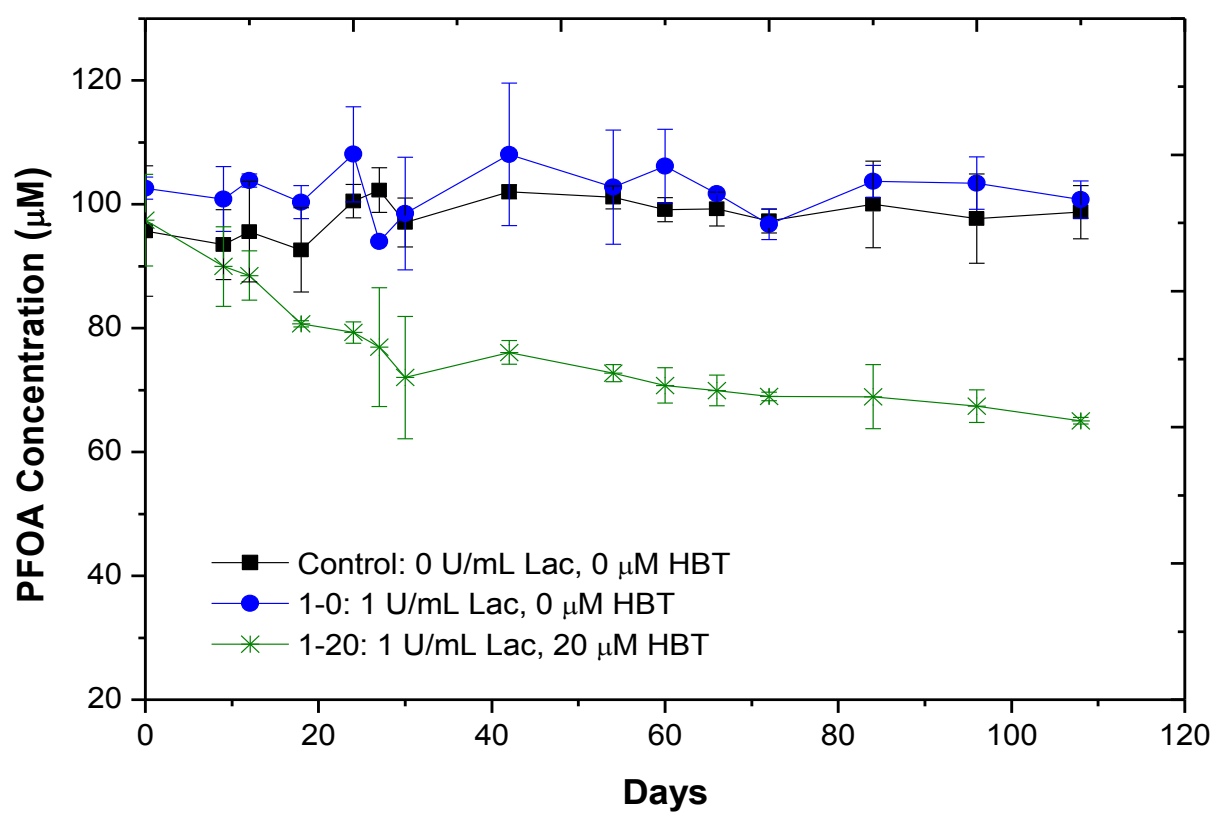

Fig. 3. Change of PFOA concentration over time in laccase-mediated ECOHRs with addition of 0.2 mmole $\mathrm{L}^{-1} \mathrm{Fe}^{3+}$. The initial PFOA nominal concentration is $100 \mu$ mole $\mathrm{L}^{-}$ 1. Control: the positive control to which no laccase or HBT was added; 1-0: $1 \mathrm{U} \mathrm{mL}^{-1}$ laccase added every $6 \mathrm{~d}$ but no HBT; 1-20: $1 \mathrm{U} \mathrm{mL}^{-1}$ laccase and $20 \mu$ mole L $^{-1} \mathrm{HBT}$ added every $6 \mathrm{~d}$. The error bars denote the standard deviation of three replicates. 


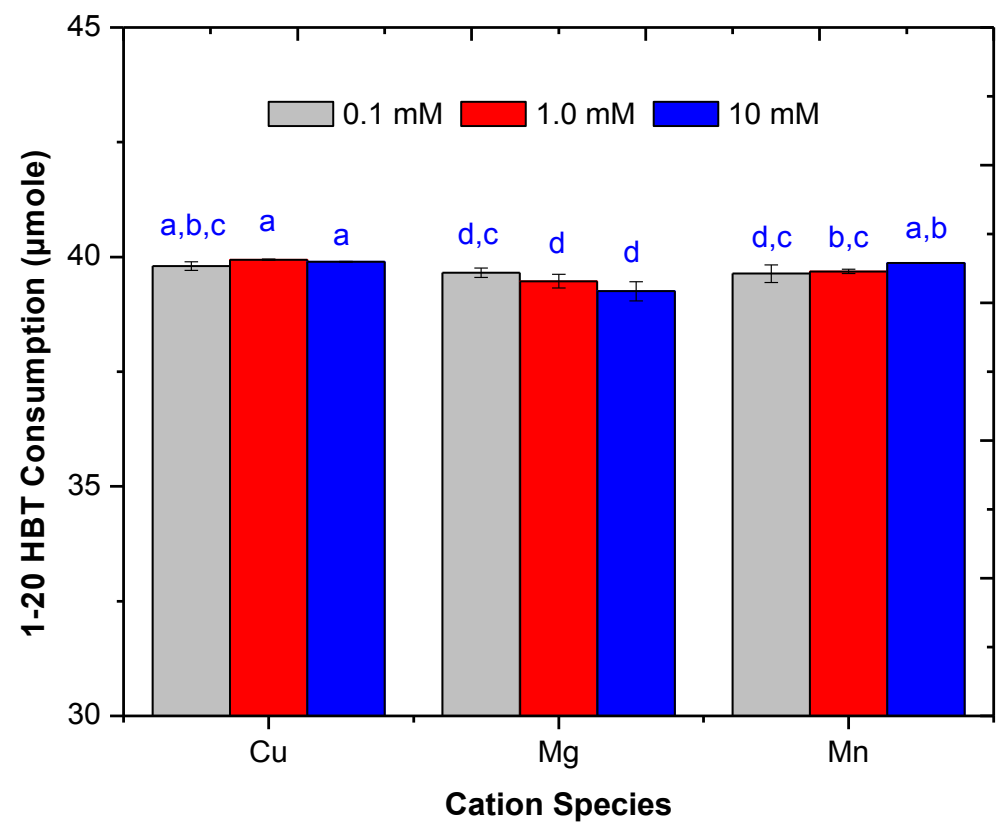

Fig. 4. HBT conversion during the ECOHRs degradation of PFOA mediated by $1 \mathrm{U} \mathrm{mL}^{-1}$ laccase and $20 \mu$ mole $\mathrm{L}^{-1}$ HBT with the presence of $0.1 / 1.0 / 10$ mmole $\mathrm{L}^{-1}$ $\mathrm{Cu}^{2+} / \mathrm{Mg}^{2+} / \mathrm{Mn}^{2+}$. The error bars denote the standard deviation of three replicates. The bars assigned by different letters indicate a significant difference at $\mathrm{P} \leq 0.05$. 


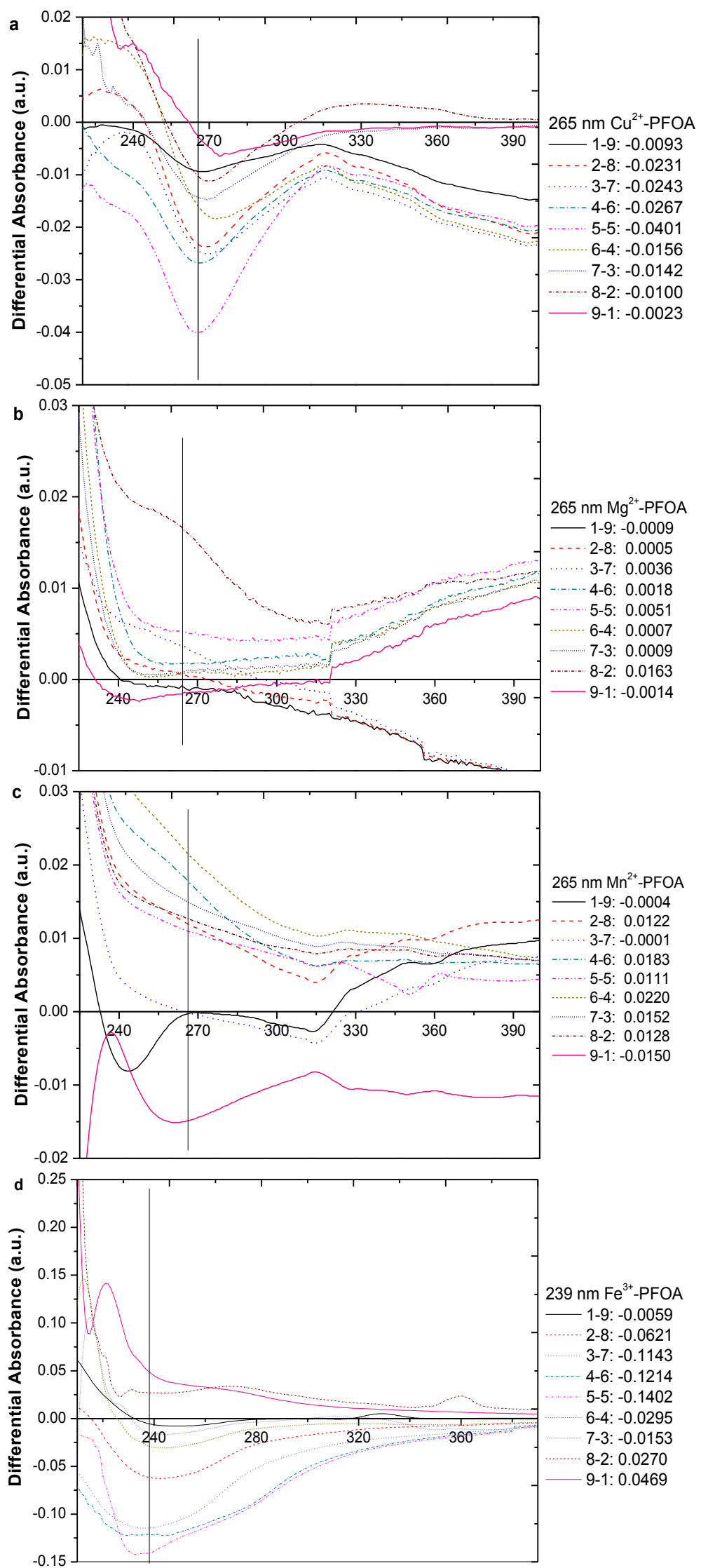


Fig. 5. UV-Vis differential absorbance spectra (DAS) calculated according to the data recorded at varying metal ion to PFOA ratios while maintaining their combined concentrations at constant level $\left(0.8\right.$ mmole $\mathrm{L}^{-1}$ for $\mathrm{Cu}^{2+} / \mathrm{Mg}^{2+} / \mathrm{Mn}^{2+}$ and 0.2 mmole $\mathrm{L}^{-1}$ for $\mathrm{Fe}^{3+}$ ) at all time. (a) $\mathrm{Cu}^{2+}-\mathrm{PFOA}$ DAS determined at $\mathrm{pH} 4.9$; (b) $\mathrm{Mg}^{2+}-\mathrm{PFOA}$ DAS determined at $\mathrm{pH} 7.0$; (c) $\mathrm{Mn}^{2+}$-PFOA DAS determined at $\mathrm{pH}$ 6.5; (d) $\mathrm{Fe}^{3+}$-PFOA DAS determined at $\mathrm{pH} 2.9$. 

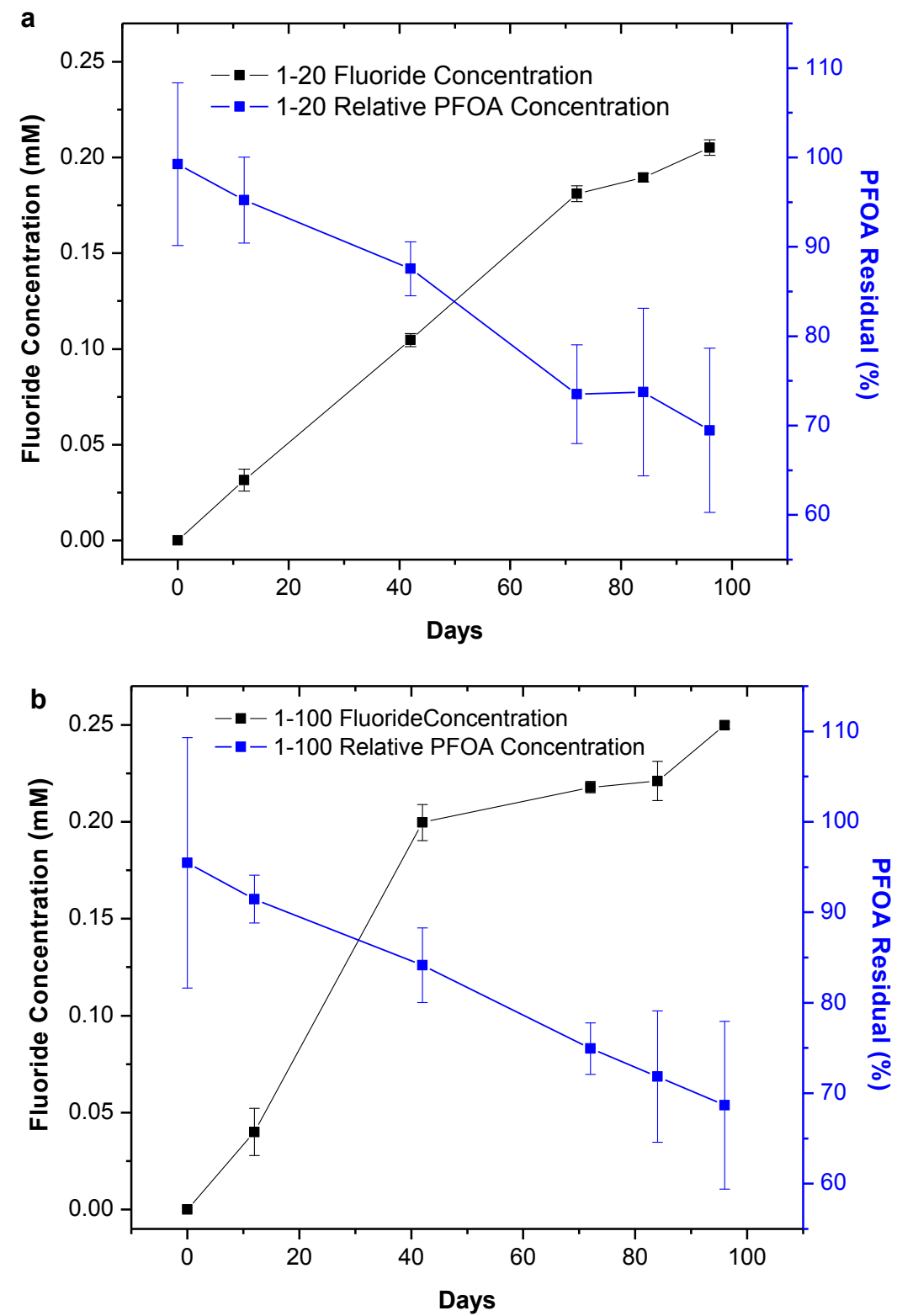

Fig. 6. Change of fluoride concentration and PFOA residual over time (initial PFOA nominal concentration $=100 \mu$ mole $\mathrm{L}^{-1}$ ) as mediated by laccase in the presence of HBT. (a) 1-20: $1 \mathrm{U} \mathrm{mL}^{-1}$ laccase and $20 \mu$ mole $\mathrm{L}^{-1} \mathrm{HBT}$ added every $6 \mathrm{~d}$; (b) 1-100: $1 \mathrm{U} \mathrm{mL}^{-1}$ laccase and $100 \mu$ mole $\mathrm{L}^{-1}$ HBT added every $6 \mathrm{~d}$. The PFOA residual is calculated by dividing the PFOA concentration in the reaction sample by that in the control (without laccase or HBT) sampled at the same time. The error bars denote the standard deviation of three replicates. 
Table 1. Molecular formulas, theoretical and measured masses of deprotonated molecule ions $[\mathrm{M}-\mathrm{H}]^{-}$, mass accuracy $(\mathrm{ppm})$ and possible structures of tentative PFOA degradation products from ECOHRs in the mineral buffer and $10-\mathrm{mmole}^{-1} \mathrm{Cu}^{2+}$ solution.

\begin{tabular}{|c|c|c|c|c|c|c|}
\hline \multirow{2}{*}{ No } & \multirow{2}{*}{ Formula } & \multicolumn{2}{|c|}{$[\mathrm{M}-\mathrm{H}]^{-}$} & \multirow{2}{*}{$\begin{array}{l}\text { Mass } \\
\text { accuracy } \\
(\mathrm{ppm})\end{array}$} & \multirow{2}{*}{$\begin{array}{l}\text { Tentative product } \\
\text { structure }\end{array}$} & \multirow{2}{*}{ Buffer } \\
\hline & & Theoretical & Experimental & & & \\
\hline 1 & $\mathrm{C}_{4} \mathrm{HF}_{7} \mathrm{O}$ & 196.9843 & 196.9840 & -1.5 & $\mathrm{HO}-\mathrm{CF}_{2} \mathrm{CF}_{2} \mathrm{CF}=\mathrm{CF}_{2}$ & MB \\
\hline 2 & $\mathrm{C}_{8} \mathrm{H}_{13} \mathrm{~F}_{3} \mathrm{~N}_{4} \mathrm{O}_{2}$ & 253.0918 & 253.0916 & -0.7 & $\underset{\prod_{\mathrm{NH}_{2}}^{\mathrm{O}}}{\mathrm{HOCHCH}}$ & MB \\
\hline 3 & $\mathrm{C}_{12} \mathrm{H}_{14} \mathrm{~F}_{4} \mathrm{O}_{2}$ & 265.0857 & 265.0857 & -0.1 & $\mathrm{CH}_{3}(\mathrm{CH}=\mathrm{CH})_{2} \mathrm{CH}_{2} \mathrm{C}_{2} \mathrm{~F}_{4} \mathrm{CH}_{2} \mathrm{CH}=\mathrm{CHCO}_{2}$ & MB \\
\hline 4 & $\mathrm{C}_{11} \mathrm{H}_{11} \mathrm{~F}_{4} \mathrm{~N}_{3} \mathrm{O}_{2}$ & 292.0714 & 292.0702 & -4.2 & & MB \\
\hline 5 & $\mathrm{C}_{17} \mathrm{H}_{26} \mathrm{~F}_{4} \mathrm{O}_{3}$ & 353.1744 & 353.1729 & -4.5 & $\mathrm{C}_{2} \mathrm{H}_{4} \mathrm{CH}=\mathrm{CHC}_{9} \mathrm{H}_{18} \mathrm{CHO}$ & MB \\
\hline 6 & $\mathrm{C}_{11} \mathrm{H}_{8} \mathrm{~F}_{9} \mathrm{~N}_{3} \mathrm{O}$ & 368.0451 & 368.0457 & 1.7 & & MB \\
\hline 7 & $\mathrm{C}_{10} \mathrm{H}_{9} \mathrm{~F}_{2} \mathrm{~N}_{3} \mathrm{O}_{2}$ & 240.0590 & 240.0595 & 1.9 & & $\mathrm{Cu}^{2+}$ \\
\hline 8 & $\mathrm{C}_{9} \mathrm{H}_{11} \mathrm{~F}_{3} \mathrm{~N}_{2} \mathrm{O}_{3}$ & 251.0649 & 251.0655 & 2.4 & 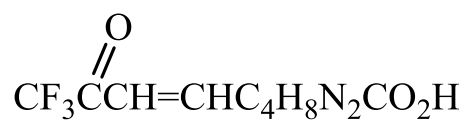 & $\mathrm{Cu}^{2+}$ \\
\hline 9 & $\mathrm{C}_{8} \mathrm{H}_{10} \mathrm{~F}_{4} \mathrm{~N}_{2} \mathrm{O}_{4}$ & 273.0504 & 273.0510 & 2.2 & $\mathrm{FCH}_{2} \mathrm{~N}=\mathrm{NCCC}_{4} \mathrm{H}_{8} \mathrm{OCCF}_{3}$ & $\mathrm{Cu}^{2+}$ \\
\hline 10 & $\mathrm{C}_{7} \mathrm{H}_{5} \mathrm{~F}_{9} \mathrm{~N}_{2} \mathrm{O}$ & 303.0185 & 303.0181 & -1.45 & $\stackrel{\mathrm{O}}{\mathrm{HCF}_{2} \mathrm{~N}=\mathrm{NC}_{2} \mathrm{H}_{4} \mathrm{C}_{3} \mathrm{~F}_{7}}$ & $\mathrm{Cu}^{2+}$ \\
\hline
\end{tabular}

MB: mineral buffer solution

$\mathrm{Cu}^{2+}: 10$-mmole $\mathrm{L}^{-1} \mathrm{Cu}^{2+}$ solution 
Graphic abstract

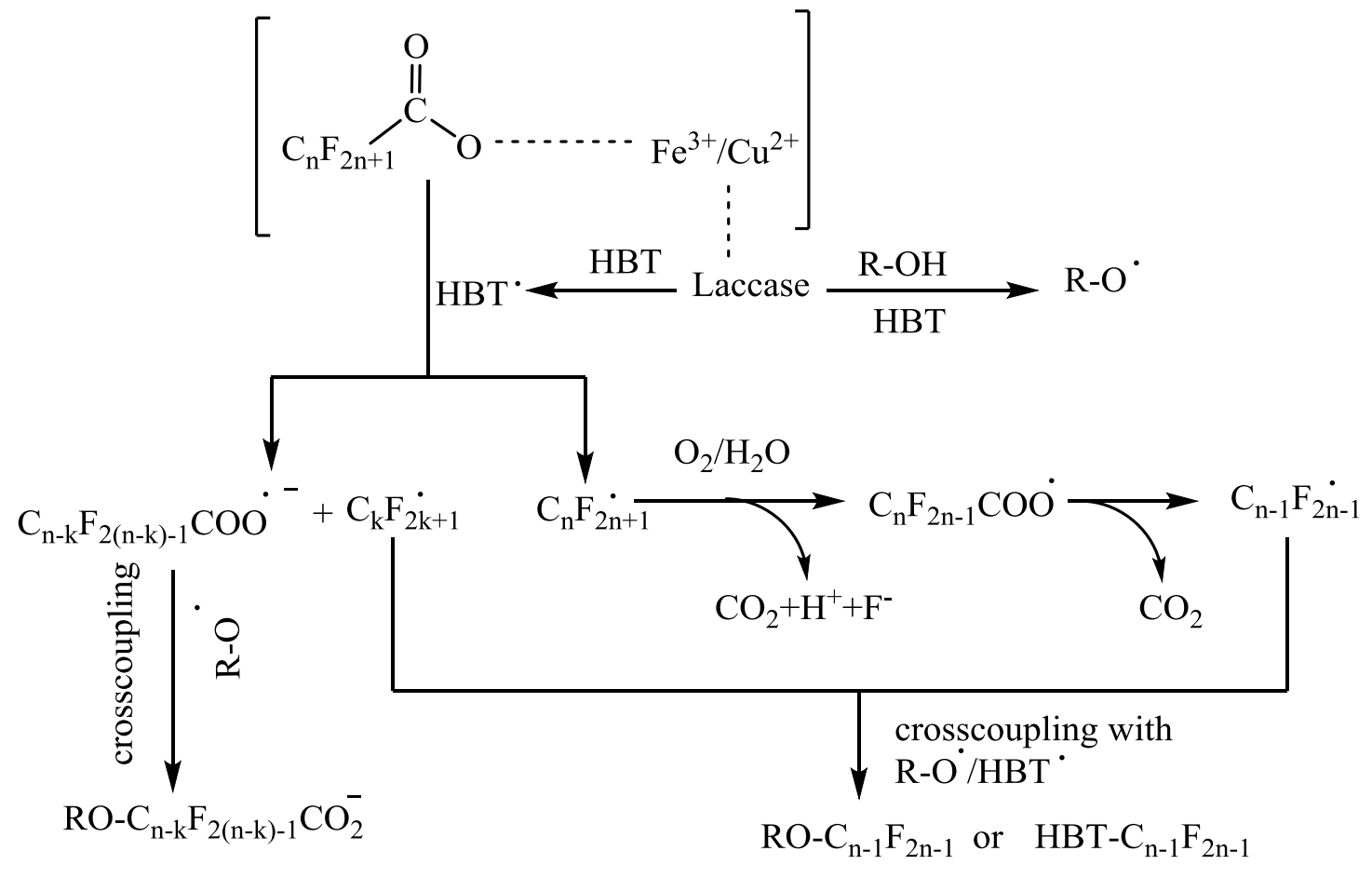

